\title{
Comparison of ELISA, SPACE, and electron microscopy for the routine diagnosis of rotavirus infection
}

\author{
RA WALL, BJ MELLARS, P LUTON, S BOULDING \\ From the Department of Microbiology, University College Hospital, London WCIE 6AU
}

SUMMARY Previous studies on the serological diagnosis of rotavirus infection have utilised localli produced antibodies. In this study we have compared two commercially produced assays, ain ELISA (Rotazyme, Abbott) and a newly developed assay-solid phase aggregation of couple erythrocytes (SPACE) (Wellcome Research Laboratories), with electron microscopy (EM).

The SPACE test appeared less sensitive than EM. The ELISA was shown to be as sensitive as EM but more versatile. Our experience suggests that the ELISA could be successfully incorporated int the routine of any diagnostic laboratory.

Rotaviruses are now accepted as the most important known aetiological agents in acute non-bacterial gastroenteritis in infancy and childhood. ${ }^{1}$ Since the first recognition of the virus in human stools, ${ }^{2}$ electronmicroscopy (EM) has been the major method by which diagnosis has been established. Because of the limitations of EM however, other diagnostic techniques have been developed. While cell culture has been achieved, ${ }^{3}$ it lacks routine practicality, and the alternative diagnostic approach is serological. A variety of techniques have been studied, including complement fixation, ${ }^{4}$ counter current immunoelectrophoresis, ${ }^{5}$ radioimmunoassay (RIA) $^{6}$ and enzyme linked immunosorbent assay (ELISA). ${ }^{7}$ Of these RIA and ELISA are considered to achieve or exceed the sensitivity of EM.

More recently the technique known as solid phase aggregation of coupled erythrocytes (SPACE) has been described for detecting rotavirus. ${ }^{8}$ The technique is similar to solid phase RIA and ELISA but utilises antibody-coated red blood cells as the indicator system instead of radioisotopes or enzymes.

Until recently however, none of these serological tests has been available commercially, thus limiting their widespread application. An ELISA for rotavirus is now marketed (Rotazyme, Abbott) and a SPACE test may be marketed in the future.

The current study was therefore undertaken to compare EM, ELISA and SPACE for detecting rotavirus and to assess the use of these techniques in a routine diagnostic laboratory.

Accepted for publication 22 May 1981

\section{Material and methods}

Eighty-nine consecutive stool samples submitted the Department of Clinical Microbiology, UCH, f evidence of rotavirus were evaluated. Each sample was coded and tested without knowledge of the results obtained by other tests.

\section{ELECTRON MICROSCOPY}

Approximately $1 \mathrm{ml}$ of stool was diluted $1 / 10$ 而 distilled water and shaken. The suspension was the mixed well with an equal volume of arcton 113 (ICP) and centrifuged at $3000 \mathrm{rpm}$ in a bench centrifuge for $30 \mathrm{~min}$. The supernatant was filtered through pore size of $0.45 \mu \mathrm{m}$ (millipore SA) and the filtrae spun at $35000 \mathrm{rpm}(139000 \mathrm{~g})$ for one hour in an OTD-50 ultracentrifuge (Swingout Rotor AH650\%. The resultant pellet was resuspended in 0.1 . distilled water, stained with $2 \%$ phosphotungst acid, and examined in a Hitachi H500 electrofs microscope.

\section{SPACE}

SPACE was carried out as previously described using materials donated by Wellcome Laboratoriegs (Dr J Almeida). Flexible mitrotitre plates with U-shaped wells were coated with $100 \mu l$ guinea pig antibody in $0.01 M$ carbonate buffer $\mathrm{pH} 9.5$, per wep. by incubation at $37^{\circ} \mathrm{C}$ for $2 \mathrm{~h}$ in an airtight plast $\$ \mathrm{C}$ box. The plates were washed three times in 0.005. Tween 20 in phosphate-buffered saline (PBSy 
Suspensions (1/10 and $1 / 100)$ of each stool sample were prepared in PBS. Quantities $(50 \mu \mathrm{l})$ of suspension were added per well, the plates covered, and incubated overnight at $4^{\circ} \mathrm{C}$ in an airtight box. Faecal suspensions were evacuated into Chloros using a vacuum pump. The plates were washed twice in PBS Tween and once in PBS. A further $50 \mu \mathrm{l}$ of a $0.5 \%$ suspension in PBS of goat red blood cells (RBC) coated with bovine antirotavirus antibody were added to each well. The plates were left for two hours at room temperature in a vibration free atmosphere to allow settling of the RBC. Positive results were recognised by forming a shield of cells, negative results by forming a button. Positive and negative controls were included on each plate.

\section{ELISA}

ELISA was carried out using Rotazyme (Abbott) according to the manufacturer's instructions.

An approximately $40 \%$ stool suspension was prepared in PBS and spun to clarify at $3000 \mathrm{rpm}$ in a bench centrifuge for $5 \mathrm{~min}$. The supernatant $(200 \mu \mathrm{l})$ was pipetted into one well of a reaction tray to which a bead coated with guinea pig antirotavirus antibody was added, and incubated overnight at room temperature. Each bead was then washed 4 times with distilled water. In addition, $200 \mu \mathrm{l}$ of rabbit antirotavirus antibody conjugated to horseradish peroxidase were added and incubated for one hour at $45^{\circ} \mathrm{C}$ in a water bath.

Each bead was again washed and transferred to a $3 \times \frac{1}{2}$ " plastic tube to which was added $200 \mu \mathrm{l}$ $o$-phenylenediamine $2 \mathrm{HCl}$ (OPD) substrate. The tubes were incubated in the dark for $15 \mathrm{~min}$ and the enzyme substrate reaction stopped by adding $1 \mathrm{ml} N$ $\mathrm{HCl}$. Results were read either in a spectrophotometer at $492 \mathrm{~nm}$ or by comparison with a completely colourless negative control.

\section{Neutralisation}

Stool suspension was incubated for 1 hour at $37^{\circ} \mathrm{C}$ with an equal volume of high titre antirotavirus antibody (human convalescent serum). The ELISA procedure was then repeated as above and the result compared with the stool suspension diluted $1 / 2$ with PBS. Neutralisation was considered to have occurred if either complete or $50 \%$ reduction in absorbance resulted.

\section{Results}

Eighty-nine stool samples were tested by each method and the overall results are presented in the Table. Forty-nine samples were negative by all tests. Thirty-seven samples were positive by EM. All these were also positive by ELISA, but only 33 positive by
Table 1 Results of three methods for the direction of human rotavirus in stool virus

\begin{tabular}{llll}
\hline & \multicolumn{3}{l}{ Method } \\
\cline { 2 - 4 } & EM & ELISA & SPACE \\
\hline HRV positive & 37 & 38 & 33 \\
HRV negative & 52 & 51 & 56 \\
Total specimens examined & 89 & 89 & 89 \\
\hline
\end{tabular}

SPACE. Of these 33,32 were positive by both $1 / 10$ and $1 / 100$ dilution and 1 at $1 / 10$ dilution only. Of the four negative by SPACE, three were weakly positive only, by EM and ELISA, suggesting diminished sensitivity of the SPACE test.

One stool was positive by ELISA and negative by other tests. This sample and a random selection of other ELISA positive samples were retested after prior incubation with high titre rotavirus antibody. All such samples then gave negative results by ELISA suggesting that specific antigenic reactivity had been neutralised.

Two stools were initially positive by SPACE and negative by other tests. One stool on retesting was negative by all tests, and the initial positive result was considered to result from difficulty in interpretation of the pattern of the RBC. The second stool was repeatedly weakly positive by SPACE alone. EM revealed small cubic viral particles against which calf serum was found to have antibodies. The guinea pig serum was shown to complex the particles (Dr J Almeida, personal communication, 1980) and the positive result was therefore likely to have resulted from this second antigen-antibody reaction.

\section{Discussion}

Since rotaviruses were first incriminated as important causes of gastrointestinal illness, EM has been the mainstay of diagnosis and the yardstick by which other diagnostic methods are judged. EM is, however, time-consuming, costly in terms of both equipment and labour, and not always readily accessible. Recent experience with handling an outbreak of rotavirus infection has confirmed the difficulties of processing a large number of specimens in a short period. ${ }^{9}$

Of the many techniques available for detecting microbial antigens, RIA and ELISA are considered the most sensitive. As a routine diagnostic tool RIA has well recognised disadvantages. ${ }^{10}$

ELISA techniques have been widely used for detecting rotavirus but all such publications have concerned locally produced antibodies. Access to these materials is not possible for the majority of diagnostic laboratories; which generally must rely on commercial kits. 
This study was therefore designed to evaluate assays which are, or may become, commercially available. Each depends on absorption of rotavirus antigen from faecal suspensions on to solid phase, with subsequent recognition of antigen by an enzyme-labelled antibody or red cell antibody indicator system. In terms of practical laboratory use, both were similar permitting results to be obtained the day after receipt of samples. Each can be adapted to provide results in one working day but overnight incubation of sample with solid phase is convenient for batching samples and may enhance sensitivity.

SPACE, however, appeared less sensitive. Results were also sometimes difficult to read, because the settling patterns of the RBC were not clear cut.

The full significance of the false positive reactions is difficult to evaluate on the number of specimens examined.

Rotazyme had the sensitivity of EM. On one occasion ELISA was positive and EM negative. This may reflect increased sensitivity, or that EM will detect only intact viral particles while immunological techniques are capable of detecting antigenic fractions. The third possibility of a false positive reaction ${ }^{11}$ was ruled out following successful neutralisation with specific rotavirus antibody. The problem of false positive results does suggest however that the specificity of a positive result should be confirmed by a blocking technique. Regrettably the necessary antibody is not an integral part of the kit. The colour reactions are nevertheless easy to read even without the aid of a spectrophotometer, and the current kit enables single assays to be performed. This study suggests that Rotazyme is a sensitive practical test which would allow the diagnosis of rotavirus shedding to be undertaken by any laboratory.

We gratefully acknowledge the assistance of $\operatorname{Dr} \mathbf{J}$ Almeida and A Shersby of the Wellcome Research Laboratories for supply of materials for the SPACE assay and for helpful advice.

\section{References}

${ }^{1}$ Rotavirus infections in infancy. Br Med J 1980;281:1162-3.

${ }^{2}$ Flewett TH, Bryden AS, Davies $H$. Virus particles in gastroenteritis. Lancet 1973;ii:1497.

${ }^{3}$ Albrey MB, Murphy AM. Rotavirus growth in bovine monolayers. Lancet 1976; i:753.

${ }^{4}$ Zissis G, Lambert JP, Deicegel D. Routine diagnosis of human rotavirus in stools. J Clin Pathol 1978;31:175-8.

${ }^{5}$ Middleton PJ, Petric M, Hewitt CM, Szymanski MT, Tam JS. Counter-immunoelectro-osmophoresis for the detection of infantile gastroenteritis virus in conventional and germ-free piglets. Infect Immun 1975;12:1276-80.

${ }^{6}$ Middleton PJ, Holdaway MD, Petric M, Szymanski MT, Tam JS. Solid phase radioimmunoassay for the detection of rotavirus. Infect Immun 1977;14:439.

7 Yolken RH, Kim HW, Clem T, et al Enzyme linked immunosorbent assay for dection of human reovirus-like agent of infantile gastroenteritis. Lancet 1977;ii:263.

${ }^{8}$ Bradburne AF, Almeida JD, Gardner PS, Moosai RB, Nash AA, Coombs RRA. A solid-phase system (SPACE) for the detection and quantification of rotavirus in faeces. J Gen Virol 1979;44:615-23.

${ }^{9}$ Hildreth C, Thomas M, Ridgway GL. Rotavirus infection in an obstetric unit. Br Med $J 1981 ; 282: 231$.

10 Voller A, Bartlett A, Bidwell DE. Enzyme immunoassays with special reference to ELISA techniques. J Clin Pathol $1978 ; 31: 507-20$.

$"$ Yolken RH, Stopa PJ. Analysis of nonspecific reactions in enzyme linked immunosorbent assay testing for human rotavirus. J Clin Microbiol 1979;10:703-7.

Requests for reprints to: Dr RA Wall, Department of Microbiology, University College Hospital, London WC1E 6AU, England. 